\title{
Focus Point on Scientific Research in Conservation Science
}

\begin{abstract}
Published online: 9 December 2019 - (c) Società Italiana di Fisica / Springer-Verlag GmbH Germany, part of
\end{abstract} Springer Nature, 2019

This Focus Point is related to the 3rd edition of the International Conference on Innovation in Art Research and Technology (inArt 2018), held in the Central Palace of the University of Parma (Italy) on 26-29 March 2018. It followed previous editions, held in Evora (Portugal) in 2013, and in Ghent (Belgium) in 2016. The congress proved to be an international reference event for the people involved in scientific research applied to the conservation and knowledge of the artistic, historical and archaeological heritage. The congress reached 130 participants from 18 Countries, sharing their research by means of 44 oral presentations and 62 posters, involving a total amount of 430 different authors. The participation of companies linked to the world of scientific analysis, in particular spectroscopy and scientific publishing was also wide. The focus of the conference was on the research and innovation for the protection and knowledge of the artistic heritage. Particular attention was put on non-invasive investigation techniques, new materials for restoration respectful of artifacts and environment, products for the prevention of corrosion and of degradation, self-cleaning materials. Presentations were devoted to the study of many different art objects and materials, including paintings (pigments, dyes, binders), textiles, manuscripts, buildings and building materials (metals, glasses, gems, bones and ivory). The analyzed objects spanned a huge time interval, ranging from antiquity (ancient Egypt) to contemporary art. Many different techniques were involved, including spectroscopies in the different ranges of the electromagnetic spectrum (from infrared to X-rays), visible and electron microscopy, multispectral imaging, threedimensional reconstruction, using instrumentations coming from handheld spectrometers to neutron sources or particle accelerators. Data treatment was also discussed, from databases to data integration and decision tools. This Focus Point presents 20 excellent examples of those research works.

A broad range of applications is covered, including the analysis of metalic oil lamps (C. Bottaini et al.) or the analysis of historical copper alloys (I. Żmuda-Trzebiatowska et al.). Another study examined the complex stratigraphy of antique Egyptian coffins (L. Brunel-Duverger et al.), while also a novel approach was tested for the analysis of gemstones (Adam Culka and Jan Jehlička). On the museology side, a decision support system for preventive conservation was presented (O. Schalm et al.) as well as a study on the deposition of dust on textile artefacts (P. Uring et al.). The anthraquinone dyes of textiles were studied by using surface-enhanced Raman spectroscopy (A. Botto et al.). Proteinaceous binding media can be studied using fluorescent labels (Ooi Su Yin et al.). Typical for this type of studies is that often multi-analytical approaches are used, such as when studying Moroccan illuminated manuscripts (G. Idrissi et al.), a polychrome cork model by A. Chichi (A. Rousaki et al.), 20th Century paintings (F. Fiorillo et al..), during the Leman Album project (R. Manca et al.), or when analysing a Bohemian late-Gothic altarpiece (H. Dáňová et al.). Some studies investigate original antique building materials, like mediaeval tiles and mortars from Nonantola, Modena, Italy (M. Bergamo et al.), while other studies focus on the treatments and cleaning approaches of limestones (L. Fornasini et al.) and mortar mock-ups (V. Brunello et al.). In one case study a pair of Goan paintings were examined (V. Antunes et al.), while in another study a six-colour relief print was dated (A. Sodo et al.). Another particular case covers the in situ analysis of modern paintings on a glass substrate (C. Mense et al.). Finally, the protection of the territory received attention in the analysis of buildings damaged by earthquakes in Italy (G. Roselli et al.). 
All these studies, as presented during the 3rd edition of the inArt conference, witness the possibilities and the fundamental importance of the continuous collaboration between different competences. They stress the importance of the study and the conservation of artworks, respecting the objects and the environment, deepening and integrating the obtained knowledge. Chemists, physicists, biologists, geologists as well as art historians, conservators, restorers, architects, computer scientists, engineers, and many other professionals will be called again to share their abilities and points of view. This kind of cross-cutting collaboration (on the international as well as the national levels) is fundamental in this particular scientific field. We are confident that the next edition of the International Conference on Innovation in Art Research and Technology (inArt 2020), that will be held in Paris, April 14-17, 2020, will give further important contribution.

Danilo Bersani, Ludovic Bellot-Gurlet, and Peter Vandenabeele

Guest Editors 